\title{
EVALUASI ASPEK FINANSIAL PENGHEMATAN BAHAN BAKAR BENSIN MENJADI CNG (COMPRESSED NATURAL GAS) UNTUK MOBIL PRIBADI
}

\author{
Ika Kurniaty \\ Program Studi Kimia, Fakultas Teknik, Universitas Muhammadiyah Jakarta \\ Jalan Cempaka Putih Tengah 27 Jakarta 10510 \\ ika.kurniaty@ftumj.ac.id
}

\begin{abstract}
The number of vehicles that increase have a bad influence on air quality and cause of pollution. Currently, the fuel for automotive still depends on fuel oil, while the exploration of oil reserves in Indonesia is insufficient to supply of domestic demand. The alternative fuels as a substitute for a primary fuel be required such as CNG (Compressed Natural Gas) for vehicles. The aims of this research is to determine the fuels mileage, cost savings and return of investment for private car users that switch into CNG as a secondary fuel. The method that used in this research is study of literature, collect the data such as theory of CNG for vehicles, convertion tools, prices of petrol (RON/Research Octane Number 90, 92) and CNG, petrol and CNG high heating value, the fuel consumption data of private cars, then proceed the data and analyzed it. The results of this research is consuming 1 liter of petrol (RON 90, 92) to a distance of $12 \mathrm{~km}$, if using CNG fuel will cover a distance of 13.5 $\mathrm{km}$. Private cars users that using CNG as an alternative fuel will have IDR 20.688 per day for savings when switch from petrol RON 90, then reached IDR 7 million during a year and obtaine a payback after 4.5 years. If switch from petrol RON 92, will receive the savings to IDR 23,250 per day and IDR 8 million in a year with the return of investment cost after 4 years.
\end{abstract}

Keywords : Compressed Natural Gas, Conversion, Private cars, RON 90, 92

ABSTRAK, Jumlah kendaraan bermotor sebagai sarana transportasi yang meningkat mempunyai pengaruh buruk terhadap kualitas udara dan penyebab terjadinya pencemaran. Pemakaian bahan bakar yang digunakan kendaraan saat ini masih tergantung dengan bahan bakar minyak, sedangkan cadangan minyak yang di eksplorasi di Indonesia semakin tidak dapat memenuhi kebutuhan dalam negeri dan harus mengimport. Bahan bakar alternatif sebagai pengganti bahan bakar primer sangat diperlukan seperti penggunaan bahan bakar gas layaknya CNG (Compressed Natural Gas) untuk kendaraan bermotor. Penelitian ini bertujuan untuk mengetahui jarak tempuh bahan bakar CNG, penghematan biaya, dan pengembalian modal pengguna mobil pribadi yang beralih ke CNG. Metode yang digunakan adalah studi pustaka, pengumpulan data seperti teori tentang CNG, konverter kit, harga bahan bakar (pertalite, pertamax, CNG), jarak tempuh kendaraan berbahan bakar minyak, nilai kalor BBM dan CNG, kemudian menganalisa data-data tersebut. Hasil penelitian ini adalah konsumsi 1 liter bahan bakar minyak (pertalite, pertamax) dapat menempuh jarak $12 \mathrm{~km}$, jika menggunakan bahan bakar CNG 1 Isp (liter setara premium) akan menempuh jarak 13.5 $\mathrm{km}$. Pengguna mobil pribadi yang menggunakan CNG sebagai bahan bakar akan memperoleh biaya penghematan sebesar Rp 20.688 per hari jika beralih dari pertalite, sehingga dalam waktu 1 tahun mencapai Rp 7 juta dan memperoleh pengembalian modal setelah 4.5 tahun. Jika beralih dari bahan bakar pertamax, biaya penghematan sebesar Rp 23.250 per hari, dalam waktu 1 tahun dihasilkan biaya penghematan sebesar Rp 8 juta dengan pengembalian modal hingga 4 tahun.

Kata kunci : CNG, Konversi, Mobil Pribadi, Pertalite, Pertamax 


\section{PENDAHULUAN}

Meningkatnya jumlah kendaraan bermotor sebagai sarana transportasi mempunyai pengaruh buruk terhadap kualitas udara dan penyebab terjadinya pencemaran. Polutan hasil pencemaran yang bersumber dari gas buang keluaran knalpot, tangki bensin dan karburator menghasilkan gas beracun yang antara lain adalah karbon monoksida, hidrokarbon dan NOx. Pencemaran tersebut berdampak terhadap pemanasan global, kerusakan lapisan ozon dan pencemaran udara (Yuswono, 1997). Pemakaian bahan bakar yang digunakan kendaraan saat ini masih tergantung dengan bahan bakar minyak, dimana cadangan minyak yang di eksplorasi di Indonesia semakin tidak dapat memenuhi kebutuhan dalam negeri dan harus mengimport (Hartanto, 2010). Jika minyak mentah mengalami kenaikan dapat mengakibatkan pasokan bahan bakar minyak yang tidak stabil untuk sampai ke masyarakat (BS \& Alam, 2013). Saat ini sangat dibutuhkan bahan bakar alternatif yang dapat menggantikan bahan bakar konvensional yang sesuai dengan spesisfikasi mesin kendaraan yang berbasis minyak bumi seperti CNG (Compressed Natural Gas).

\section{CNG (Compressed Natural Gas)} merupakan gas alam terkompresi yang dapat digunakan sebagai bahan bakar alternatif bersih lainnya seperti bensin (bensin) dan solar untuk kendaraan. Meskipun ada sumber daya yang besar yang tersedia dari gas alam, tetapi belum diterima secara luas sebagai bahan bakar alternatif (Farzaneh-Gord, et al., 2011), maka dari itu peneliti ingin menganalisis kelayakan dari bahan bakar CNG dari segi keekonomian sebagai bahan bakar sekunder untuk kendaraan bermotor khususnya di Indonesia.

Compressed Natural Gas atau CNG adalah bahan bakar yang berasal dari gas bumi dengan unsur utama gas metana yang dimampatkan, di pertahankan dan disimpan di dalam sebuah bejana tekan yang dirancang khusus. CNG mengandung komponen utama berupa metana $\left(\mathrm{CH}_{4}\right)$ dan etana $\left(\mathrm{C}_{2} \mathrm{H}_{8}\right)$. CNG dibuat dengan melakukan kompresi metana yang diekstrak dari gas alam (S.Zaini, et al., 2013) . CNG memiliki hidrogen yang lebih tinggi untuk rasio karbon dari pada bahan bakar minyak dan menghasilkan lebih sedikit $\mathrm{CO}_{2}$ per unit energi (L.Kirk, et al., 2014). CNG memliki Harga yang lebih murah dari bahan bakar minyak, kadar oktan yang lebih tinggi, emisi gas buang yang lebih bersih yang ditunjuukan pada tabel 1 dan ramah lingkungan jika di bandingkan dengan bahan bakar minyak. Namun perlu adanya modifikasi pada mesin diesel sebelum bisa menggunakan alternatif bahan bakar gas (BS \& Alam, 2013).

Tabel 1. Perbandingan Emisi Buang Bahan Bakar (Jha, et al., 2012)

\begin{tabular}{|c|c|c|c|}
\hline $\begin{array}{l}\text { Bahan } \\
\text { Bakar }\end{array}$ & $\begin{array}{l}\text { CO } \\
(\mathrm{g} / \mathrm{km})\end{array}$ & $\begin{array}{l}\mathrm{HC} \\
(\mathrm{g} / \mathrm{km})\end{array}$ & $\begin{array}{l}\text { NOx } \\
\text { (g/km) }\end{array}$ \\
\hline Bensin & 0.256 & 0.065 & 0.09 \\
\hline CNG & 0.12 & 0.042 & 0.07 \\
\hline LPG & 0.234 & 0.039 & 0.11 \\
\hline
\end{tabular}

Kendaraan berbahan bakar gas membutuhkan rangkaian komponen tambahan yang disebut konverter kit. Konverter kit merupakan rangkaian komponen khusus untuk mengkonversi /mengubah pemakaian bahan bakar minyak ke CNG yang dimasukkan/diinjeksikan ke dalam ruang bahan bakar (Penyusun, 2012). Alat tersebut berfungsi untuk mengubah energi dari bahan bakar minyak ke gas, atau sebaliknya (dual fuel). Alat konversi ini dibutuhkan karena kendaraan yang dipasarkan mempunyai desain mesin yang berbahan bakar minyak. Desain tangkipun berbeda karena berat jenis gas 
tersebut lebih ringan dari udara sehingga mudah terbang. Untuk mengatasi itu baik tangki maupun pipa-pipa yang menghubungkan ke konverter kit, harus benar-benar baik, tidak boleh ada yang bocor dan mampu menerima tekanan pada 300 Psi (pound per square inch) (Indartono, 2012).

\section{METODE}

Metode dalam pelaksanaan penelitian ini sesuai dengan skema pada gambar 1 yang terbagi beberapa tahap sebagai berikut :

\section{Studi Literatur/Teori}

Penyusunan penelitian ini sangat membutuhkan teori - teori pendukung untuk mengembangkan ide atau gagasan, metodologi pelaksanaan dan parameter yang digunakan untuk menganalisis semua data yang ada dalam penelitian. Beberapa teori tersebut seperti pengertian CNG (Compressed Natural Gas), perkembangan CNG sebagai bahan bakar kendaraan bermotor, konverter kit untuk mobil pribadi

2. Pengumpulan Data

Pengumpulan data dilakukan setelah menelaah apa saja teori - teori pendukung yang dibutuhkan. Data data yang dibutuhkan selama penelitian adalah harga bahan bakar bensin jenis pertalite (RON/Research Octane Number 90, pertamax (RON 92), harga bahan bakar CNG, jarak tempuh bahan bakar BBM dan CNG untuk mobil pribadi, HHV (High Heating Value)/nilai kalor BBM dan CNG

3. Analisis Data

Data - data yang telah lengkap dikumpulkan kemudian dilakukan analisis lebih lanjut. Data - data tersebut dianalisis melalui beberapa perhitungan seperti perhitungan penghematan bahan bakar, biaya konversi, jarak tempuh bahan bakar CNG (km), POT (Pay Out Time) / PBP (Pay Back Periode)
- Penghematan bahan bakar Penghematan bahan bakar didapat dari selisih harga konsumsi bahan bakar bensin (pertalite, pertamax) dengan CNG perhari, kemudian diakumulasi dalam 1 tahun

- Jarak tempuh CNG (km) Untuk menghitung jarak tempuh CNG $(\mathrm{km})$ digunakan rumus sebagai berikut

$$
\frac{\text { Jarak Tempuh BBM }(\mathrm{km}) \times \text { HHV CNG }\left(\frac{M \mu}{K g}\right)}{H H V B B M\left(\frac{M J}{K g}\right)} \ldots 1
$$

Keterangan :

HHV (High Heating Value)/nilai kalor bahan bakar

- Depresiasi

Depresiasi suatu alat dapat dihitung dari biaya peralatan yang dikeluarkan kemudian dibagi dengan umur alat yang telah ditetapkan.

- POT (Pay Out Time)

Payback periode atau pay out time atau disebut juga sebagai periode pengembalian dari suatu proyek adalah waktu yang dibutuhkan agar jumlah penerimaan sama dengan jumlah investasi atau biaya. POT menunjukkan lama modal investasi dapat kembali. Persamaan POT adalah sebagai berikut (Kurniaty, 2013) :

$$
\sum_{t=0}^{P B P} X t=0
$$

4. Hasil Analisis

Hasil analisis didapat setelah semua data - data yang terkumpul diolah menggunakan parameter - parameter dalam studi kelayaan. Hasil tersebut kemudian menghasilkan bahasan bahasan lebih lanjut tentang evaluasi CNG (Compressed Natural Gas) sebagai bahan bakar untuk mobil pribadi dari sisi finansial 


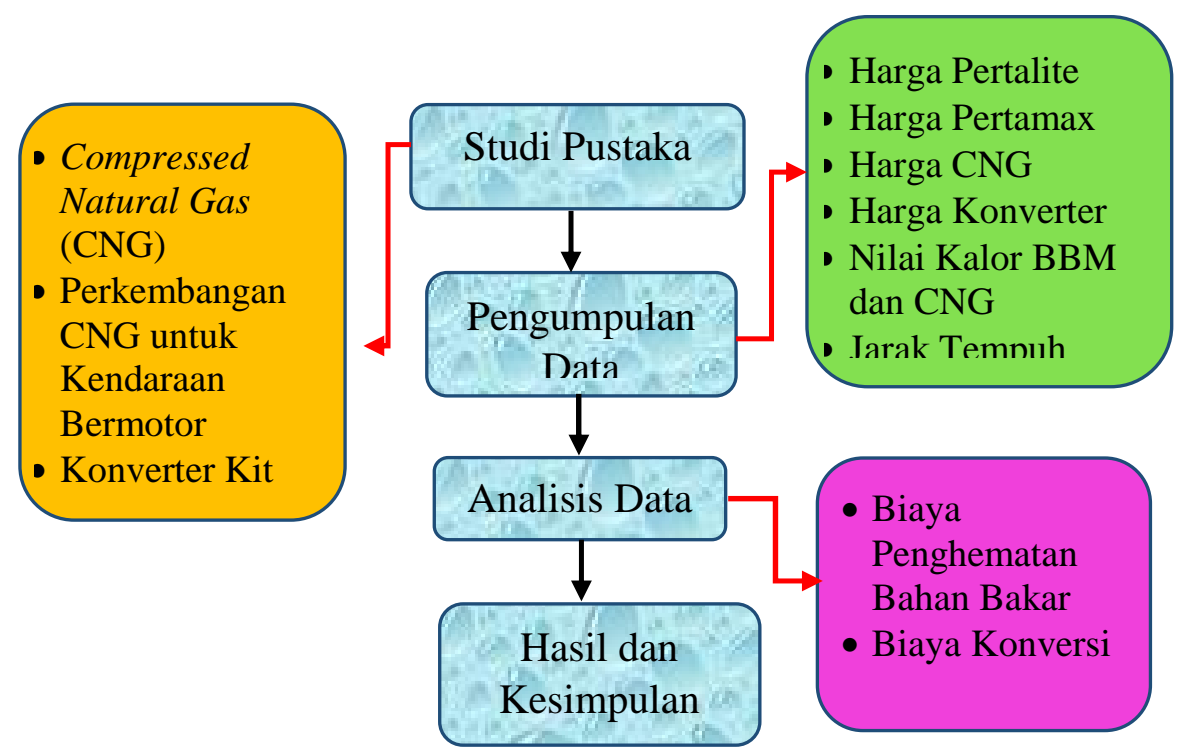

Gambar 1. Skema Metode Penelitian

\section{HASIL DAN PEMBAHASAN}

Penelitian ini di klasifisikan untuk bahan bakar yang digunakan dalam kendaraan bermotor jenis mobil pribadi. Hasil penelitian ini di dapat setelah semua data terkumpul kemudian di analisis menggunakan parameter yang ada. Menurut tabel dibawah dibutuhkan asumsi beberapa data yang akan dibutuhkan untuk

perhitungan dalam analisis, seperti biaya yang harus dikeluarkan untuk pembelian konverter beserta pemasangannya, selain itu untuk biaya operasional kendaraan mobil pribadi meliputi biaya tol, parkir kendaraan selama hari kerja maupun berlibur ke suatu tempat, biaya perpanjangan STNK tiap 5 tahun, PKB (Perpanjangan Kendaraan Bermotor), biaya perawatan dan perbaikan mobil minimal 2 kali dalam setahun.
Tabel 2. Data - Data Asumsi

\section{No Asumsi data yang dibutuhkan}

\begin{tabular}{|c|c|c|}
\hline 1 & 1 tahun & $\begin{array}{l}12 \text { bulan } \\
365 \text { hari }\end{array}$ \\
\hline 2 & $\begin{array}{l}\text { Biaya konverter } \\
\text { dan } \\
\text { pemasangan }\end{array}$ & Rp 15.000.000 \\
\hline 3 & Umur alat & 10 tahun \\
\hline 4 & Biaya tol & Rp 18.000/hari \\
\hline 5 & Biaya parker & Rp 4.000/hari \\
\hline 6 & $\begin{array}{l}\text { Biaya } \\
\text { perpanjangan } \\
\text { STNK }\end{array}$ & $\begin{array}{ll}\mathrm{Rp} & 250.000 / 5 \\
\text { tahun }\end{array}$ \\
\hline 7 & $\begin{array}{l}\text { Biaya PKB } \\
\text { (Pajak } \\
\text { Kendaraan } \\
\text { Bermotor) }\end{array}$ & $\begin{array}{l}\text { Rp } \\
1.900 .000 / \text { tahun }\end{array}$ \\
\hline 8 & $\begin{array}{l}\text { Biaya } \\
\text { perawatan mobil }\end{array}$ & $\begin{array}{l}\mathrm{Rp} 1.500 .000 / 6 \\
\text { bulan }\end{array}$ \\
\hline
\end{tabular}

Berdasarkan tabel 3, mobil pribadi yang menggunakan 1 liter pertalite dan pertamax diasumsikan mempunyai jarak tempuh $12 \mathrm{~km}$. Untuk mengetahui jarak tempuh mobil pribadi jika beralih ke bahan bakar CNG, terlebih dahulu membutuhkan 
data nilai kalor masing - masing bahan bakar. Bahan bakar minyak (pertalite, pertamax) mempunyai nilai kalor 46.536 $\mathrm{MJ} / \mathrm{Kg}$ sedangkan nilai kalor CNG sebesar $52.225 \mathrm{MJ} / \mathrm{Kg}$ (Boundy, et al., 2011). Menurut hasil perhitungan di dapat bahwa 1 Isp (liter setara premium) CNG dapat menempuh jarak hingga $13.5 \mathrm{~km}$. jarak yang ditempuh mobil pribadi jika beralih dari bahan bakar minyak ke CNG mempunyai selisih sebesar $1.5 \mathrm{~km} / \mathrm{lsp}$

Tabel 3. Jarak Tempuh dan Nilai Kalor

\begin{tabular}{|c|c|c|c|}
\hline \multicolumn{4}{|c|}{ Bahan Bakar } \\
\hline $\begin{array}{l}\text { Bahan } \\
\text { Bakar }\end{array}$ & $\begin{array}{l}\text { Nilai } \\
\text { Kalor }\end{array}$ & Jarak Tempuh & \\
\hline $\begin{array}{l}\text { Pertalite } \\
\text { pertamax }\end{array}$ & $\begin{array}{l}46.536 \\
\mathrm{MJ} / \mathrm{Kg}\end{array}$ & 1 liter & $\begin{array}{l}12 \\
\mathrm{~km}\end{array}$ \\
\hline CNG & $\begin{array}{l}52.225 \\
\mathrm{MJ} / \mathrm{Kg}\end{array}$ & $\begin{array}{l}1 \text { Isp (liter setara } \\
\text { premium) }\end{array}$ & $\begin{array}{l}13.5 \\
\mathrm{~km}\end{array}$ \\
\hline
\end{tabular}

Bahan bakar minyak sebanyak 1 liter dapat menempuh $12 \mathrm{~km}$ perjalanan, jika dalam sehari rata - rata jarak yang ditempuh sebesar $60 \mathrm{~km}$, maka akan menghabiskan 5 liter BBM (pertalite/pertamax). Data tersebut dapat digunakan untuk menghitung berapa banyak bahan bakar CNG yang digunakan dengan jarak tempuh yang sama perhari yaitu sekitar $60 \mathrm{~km}$. Untuk jarak tempuh 60 $\mathrm{km}$, mobil pribadi berbahan bakar CNG, akan membutuhkan kurang lebih 4.5 Is. Menurut hasil perhitungan dapat diketahui dengan jarak tempuh yang sama, $(60 \mathrm{~km})$ bahan bakar yang dihabiskan akan lebih hemat dengan selisih 0.5 liter jika menggunakan CNG dan biaya yang dikeluarkan juga lebih efisien. Sekarang ini harga pertalite mencapai $\mathrm{Rp} 6.900 /$ liter, pertamax Rp 7.450/liter dan CNG sebesar Rp 3.100/lsp. Tabel 4 dibawah menjelaskan bahwa untuk mobil pribadi yang akan beralih ke bahan bakar CNG dari bahan bakar pertalite akan memperoleh penghematan biaya bahan bakar sebesar Rp 20.688 perhari, dalam 1 tahun penghematan tersebut dapat mencapai Rp 7 juta. Sedangkan mobil pribadi yang beralih dari bahan bakar pertamax menuju CNG, penghematannya akan jauh lebih besar, dalam sehari sebesar Rp 23.438 sehingga akan mencapai Rp 8 juta dalam setahun.

Tabel 4. Perhitungan Biaya Penghematan Bahan Bakar Minyak dan CNG

\begin{tabular}{|c|c|c|c|}
\hline Bahan bakar & Pertalite & Pertamax & CNG \\
\hline $\begin{array}{l}\text { Jarak } \\
\text { tempuh/hari }\end{array}$ & \multicolumn{2}{|c|}{$5: 60$ (5 liter/60 km) } & $\begin{array}{l}4.46: 60 \\
(4.46 \\
\mathrm{lsp} / 60 \\
\mathrm{~km})\end{array}$ \\
\hline Harga (Rp) & 6.900/liter & 7.450/liter & $3.100 / l s p$ \\
\hline $\begin{array}{l}\text { Pemakaian } \\
\text { bahan } \\
\text { bakar/hari } \\
(\mathrm{Rp})\end{array}$ & 34.500 & 37.250 & 13.812 \\
\hline $\begin{array}{l}\text { Pemakaian } \\
\text { bahan } \\
\text { bakar/tahun } \\
(\mathrm{Rp})\end{array}$ & $\begin{array}{l}12.592 .50 \\
0\end{array}$ & $\begin{array}{l}13.596 .25 \\
0\end{array}$ & $\begin{array}{l}5.041 .21 \\
4\end{array}$ \\
\hline $\begin{array}{l}\text { Penghemata } \\
\text { n Bahan } \\
\text { Bakar/hari } \\
\text { (Rp) }\end{array}$ & 20.688 & 23.438 & - \\
\hline $\begin{array}{l}\text { Penghemata } \\
\text { n Bahan } \\
\text { Bakar/tahun } \\
(\mathrm{Rp})\end{array}$ & 7.551 .286 & 8.555 .036 & - \\
\hline
\end{tabular}

Tabel 5. Perhitungan Biaya Konversi dan Pengembalian Modal

\begin{tabular}{lll}
\hline Jenis kendaraan & \multicolumn{2}{l}{ Mobil Pribadi } \\
\hline Bahan bakar & Pertalite & Pertamax \\
\hline Biaya Peralatan (Rp) & \\
$\begin{array}{l}\text { Biaya konverter dan } \\
\text { pemasangan }\end{array}$ & 15.000 .000 \\
\hline Biaya Operasion &
\end{tabular}

\begin{tabular}{|c|c|}
\hline \multicolumn{2}{|c|}{ Biaya Operasional (Rp/tahun) } \\
\hline $\begin{array}{l}\text { Biaya bahan bakar } \\
\text { CNG }\end{array}$ & 5.041 .214 \\
\hline $\begin{array}{l}\text { Biaya perawatan dan } \\
\text { perbaikan }\end{array}$ & 3.000 .000 \\
\hline Biaya parker & 1.460 .000 \\
\hline Biaya tol & 6.570 .000 \\
\hline $\begin{array}{l}\text { Biaya pajak } \\
\text { kendaraan bermotor }\end{array}$ & 1.900 .000 \\
\hline $\begin{array}{l}\text { Biaya perpanjangan } \\
\text { STNK }\end{array}$ & 50.000 \\
\hline Depresiasi & 1.500 .000 \\
\hline Total biaya & 34.521 .214 \\
\hline Keuntungan & $\begin{array}{ll}7.551 .286 & 8.555 .036\end{array}$ \\
\hline $\begin{array}{l}\text { Pengembalian moda } \\
\text { (tahun) }\end{array}$ & 4.5 \\
\hline
\end{tabular}


Mobil pribadi yang ingin beralih menggunakan bahan bakar CNG membutuhkan peralatan instalasi tambahan yang dapat mengkonversi bahan bakar CNG ke dalam mesin mobil pribadi yang dirancang menggunakan bahan bakar minyak sebelumnya. Biaya konverter beserta pemasangan semua instalasinya diasumsikan sebesar Rp 15 juta. Untuk menghitung biaya konversi dan pengembalian modal membutuhkan biaya operasional kendaraan dan juga depresiasi. Biaya operasional meliputi biaya tol, parkir, biaya perpanjangan STNK, PKB (Perpanjangan Kendaraan Bermotor), biaya perawatan dan perbaikan mobil yang dibutuhkan dapat dilihat pada tabel 2 diatas. Biaya - biaya tersebut dihitung dalam perkiraan waktu 1 tahun yaitu 365 hari. Depresiasi didapat dengan membagi biaya yang dikeluarkan untuk konverter dengan umur alat yang telah ditentukan. Untuk keuntungan yang didapat dari biaya konversi pada tabel 4 didapat dari penghematan bahan bakar minyak yang beralih ke CNG dalam waktu 1 tahun. Keuntungan tersebut mempunyai hasil yang berbeda tergantung bahan bakar minyak (pertalite/pertamax) yang digunakan, karena masing - masing BBM tersebut mempunya harga yang berbeda untuk tiap liternya. Mobil pribadi berbahan bakar pertalite yang beralih menggunakan bahan bakar CNG akan menerima pengembalian modal setelah 4.5 tahun, sedangkan mobil pribadi yang beralih dari bahan bakar pertamax akan menerima setelah 4 tahun. Pengembalian modal tersebut dihitung melalui total semua biaya investasi dibagi dengan keuntungan dari masing - masing bahan bakar.

\section{KESIMPULAN}

1. CNG (Compressed Natural Gas) merupakan gas alam terkompresi yang dapat digunakan sebagai bahan bakar alternatif bersih lainnya seperti bensin dan solar untuk kendaraan. CNG memliki Harga yang lebih murah dari bahan bakar minyak, kadar oktan yang lebih tinggi, emisi gas buang yang lebih bersih dan ramah lingkungan di bandingkan dengan bahan bakar minyak.

2. Mobil pribadi yang mengkonsumsi 1 liter bahan bakar minyak dapat menempuh jarak $12 \mathrm{~km}$, jika menggunakan bahan bakar CNG $1 \mathrm{lsp}$ (liter setara premium) akan menempuh jarak $13.5 \mathrm{~km}$.

3. Pengguna mobil pribadi yang menggunakan CNG sebagai bahan bakar akan memperoleh biaya penghematan sebesar Rp 20.688 perhari per unit kendaraan jika beralih dari pertalite, sehingga dalam waktu 1 tahun mencapai Rp 7 juta. Jika beralih dari bahan bakar pertamax, biaya penghematan yang didapat sebesar Rp 23.250 per hari per unit kendaraan, dalam waktu 1 tahun dihasilkan biiaya penghematan sebesar Rp 8 juta.

4. Biaya konversi yang harus dikeluarkan untuk peralatan konverter dan biaya yang lain mencapai total $\mathrm{Rp} 34$ juta, untuk pengguna yang beralih dari bbm pertalite akan memperoleh pengembalian modal setelah 4.5 tahun, dan 4 tahun untuk pengguna mobil pribadi yang beralih dari bbm pertamax.

\section{DAFTAR PUSTAKA}

Boundy, B., W.Diegel, S., Wright, L. \& C.Davis, S., 2011. Biomass Energy Data Book. 4 ed. Tennessee: U.S Department of Energy. 
BS, A. W. \& Alam, R. S., 2013. Pemanfaatan Energi Alternatif Gas Alam Terkompresi Sebagai Bahan Bakar Mesin Penggerak Kapal Nelayan Tradisional. KAPAL, Volume 9, pp. 30-38.

Farzaneh-Gord, M., Deymi-Dashtebayaz, M. \& Rahbari, H. R., 2011. Studying Effect of Storage Types on Performance of CNG Filling Stations. Journal of Natural Gas Science and Engineering, Volume 3, pp. 334-340.

Hartanto, A., 2010. Kajian Kebijakan Konversi Dari BBM Ke BBG Untuk Kendaraan Di Propinsi Jawa Barat. Laporan Akhir Program Insentif Peneliti dan Perekayasa LIPI .

Indartono, 2012. Pemakaian Bahan Bakar Gas Menjadi Alternatif Bagi Kendaraan Bermotor Berbahan Bakar Premium. Gema Teknologi, April-Oktober, Volume 17, pp. 1821.

Jha, M., Singh, A., Tyagi, R. \& Verma, M., 2012. Comparative Study of Exhaust Emission of Commonly Used Fuel in an Internal Combustion Engine. Journal of Environmental Science, Computer Science and Engineering \& Technology, Desember, Volume 2, pp. 52-56.

Kurniaty, I., 2013. Analisis Pemanfaatan LPG dan CNG Sebagai Bahan
Bakar Kendaraan Bermotor di Wilayah Jawa Barat, Depok: Universitas Indonesia.

L.Kirk, J., L.Bristow, A. \& M.Zanni, A., 2014. Exploring The Market for Compressed Natural Gas Light Commercial Vehicles in The United Kingdom. Transportation Research Part D, Volume 29, pp. 22-31.

Penyusun, T., 2012. Pemberlakuan Persyaratan Teknis Rangkaian Komponen Konverter Kit Untuk Kendaraan Bermotor Secara Wajib. [Online] Available at: http://regulasi.kemenperin.go.id/sit e/download peraturan/1264

S.Zaini, et al., 2013. Analisis Ekonomis Penggunaan PLTG CNG (Compressed Natural Gas) Di Jakabaring Dalam Memenuhi Energi Listrik Waktu Beban Puncak Di Kota Palembang. Seminar Nasional Added Value of Energy Resources (AVoer), pp. 173-178.

Yuswono, L. C., 1997. Bahan Bakar Gas Sebagai Bahan Bakar Alternatif Pada Kendaraan Bermotor. Cakrawala Pendidikan, November.pp. 139-149. 


\section{Ucapan Terima Kasih}

Ucapan Terimakasih kepada para Reviewer pada Jurnal Konversi Volum 6 Nomer 1 April 2017 ini :

Prof. Dr. Ir. Slamet MT, Universitas Indonesia

Dr.Ir. Tri Yuni Hendrawati M.Si, Universitas Muhammadiyah Jakarta

Nurul Hidayati Fithriyah ST., M.Sc., Ph.D, Universitas Muhammadiyah Jakarta

Dr.Ir. Ratri Ariatmi Nugrahani MT, Universitas Muhammadiyah Jakarta

Dr.Ir. Joelianingsih MT, Institut Teknologi Indonesia

Dr. Rahmawati ST. M.Si, Universitas Sahid

Ir. Herliati MT., Ph.D, Universitas Jayabaya 